\title{
Short-term, Emergency Management of an Endodontically-treated Tooth with a Dislodged Crown
}

\author{
Mohammad Hossein Dashti* \\ Diplomate, American College of Prosthodontics, USA
}

\begin{abstract}
Recurrent caries or fracture of the remaining tooth structure under existing crowns are among the most common occurrences in restorative dentistry, which may lead to dislodgement or loss of these restorations. A short-term management of endodontically-treated teeth with dislodged crowns is discussed.
\end{abstract}

\section{Introduction}

One of the common complications in restorative dentistry is the development of recurrent caries under the existing restorations. The etiology of dental caries is the bacterial plaque which harbors the cariogenic bacteria, mainly the Streptococcus mutans and Lactobacillus species [1]. Patient's poor oral hygiene, frequent sugar intake, reduced salivary flow rate, gingival recession, and the existence of faulty restorations are among the contributing factors for dental caries initiation and progression. The cariogenic bacteria metabolize the fermentable simple sugars, such as sucrose and fructose, to produce lactic acid. Once the $\mathrm{pH}$ has reached a level low enough, the remineralization potential of dental tissues cannot compete with the rate of demineralization, and caries starts to develop [2-4].

Endodontically-treated teeth, being nonvital, add another confounding factor to this scenario since the patients do not feel the pain and discomfort associated with carious lesions in vital teeth. Therefore, the lesion may progress before it is noticed, rendering its restoration more complicated, if not impossible [5]. The purpose of this article is to report a practical approach for a short-term restoration of endodontically-treated teeth with recurrent caries under an otherwise serviceable fixed prosthesis.

\section{Case report}

A 55-year-old female with a noncontributory medical history presented with a loose metal-ceramic crown on her mandibular left first premolar. Her periapical radiograph showed an existing endodontically-treated root, a prefabricated post, and a metal-ceramic crown with an open margin (Figure 1). In addition, she was missing the rest of her posterior teeth in that quadrant. A removable partial denture had been previously made for her, but she did not feel comfortable and did not wear it, except occasionally.

The cause of crown dislodgement was determined to be inadequate remaining tooth structure and ferrule effect, improper choice of post and core system, the absence of more posterior teeth, and non-axial loads exerted by the occasional use of a removable partial denture.

\section{Several treatment options were available}

1. Extraction of the remaining root, immediate placement of an implant in the extraction socket and another implant in the first molar position, followed by fabrication of a 3-unit implant supported fixed partial denture with the second premolar as a pontic.

2. Extraction of the remaining root, placement of an implant distal to the extraction site, fabrication of an implant-assisted removable partial denture which would gain support and retention from the implant, by means of a locator attachment.

3. Performance of crown lengthening procedure and endodontic retreatment of the remaining root. Fabrication of a cast post and core, followed by a new crown.

4. Modification of the finish line by increasing the ferrule effect followed by fabrication of a cast post and core which is retrofitted to the existing crown.

Although the patient was considering the option of an implantsupported FPD as an ideal plan, she chose the last option as a more affordable and convenient short-term treatment modality.

\section{Clinical procedures}

The dislodged crown was still loosely attached to the prefabricated post, but the post was still in place and there was no sign of recurrent caries invading the canal, judging by its intact cement line (Figures 2 and 3).

1. The prefabricated post was removed by using an ultrasonic device (Dentsply Cavitron) to break the cement seal followed by careful extrusion of the post by means of a post-puller.

*Correspondence to: Mohammad Hossein Dashti, Department of Restorative Sciences and Biomaterials, Boston University Henry M. Goldman School of Dental Medicine, 100 East Newton Street, Boston, Ma 02118, USA, Fax: 617 916-5046; E-mail: mhdashti@bu.edu

Received: May 03, 2018; Accepted: May 28, 2018; Published: May 30, 2018 


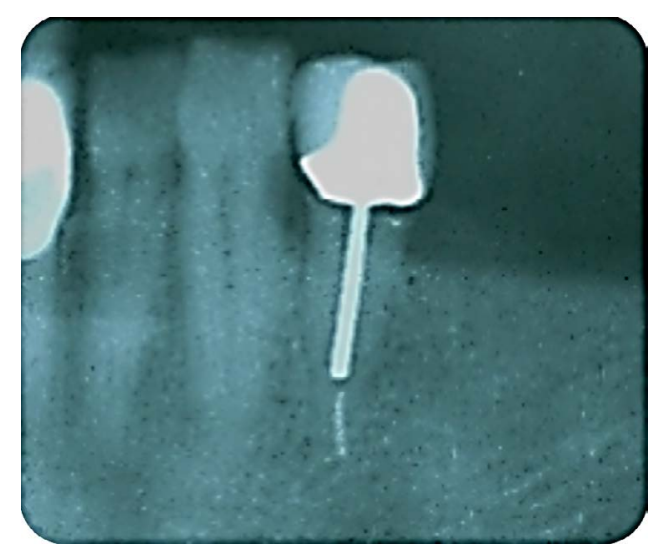

Figure 1. Periapical radiograph of the affected tooth.

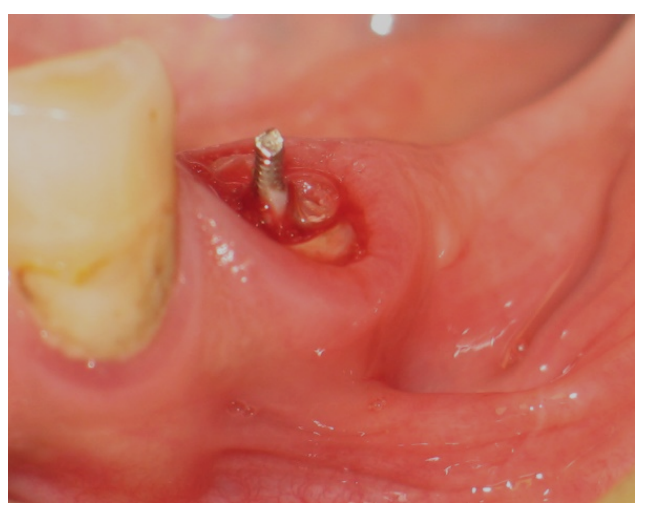

Figure 2. Remaining prefabricated post.

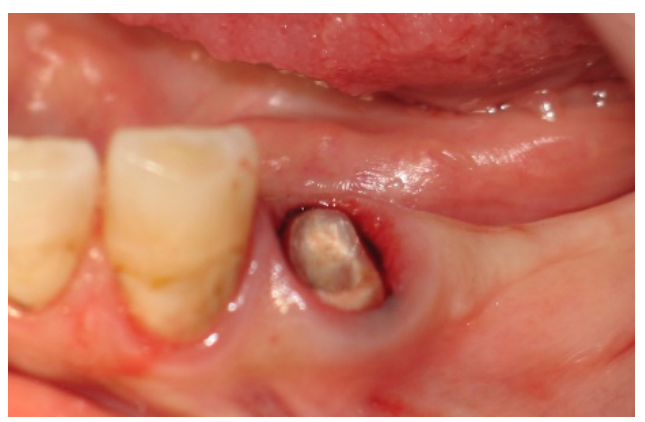

Figure 3. Prepared tooth before post and core pattern.

2. After complete removal of the remaining cement, a \#1 knitted retraction cord (Ultrapak, Ultradent) was placed into the gingival sulcus for better visibility and moisture control.

3. A $1 \mathrm{~mm}$ bevel was prepared to extend the finish line into the gingival sulcus and increase the ferrule (Figure 4).

4. Margin of the existing crown was modified to a butt-joint to improve its duplication by the pattern resin (Figure 5).

5. A post pattern was made following the standard technique with a plastic dowel (Spee-Dee point, Pupdent) and a pattern resin (GC, Inc.).

6. The intaglio of the modified crown was lubricated with a thin layer of petroleum jelly, filled with a small amount of pattern resin mixture, and inverted over the abutment tooth, verifying the correct position by patient's occlusion.
7. The crown was removed, and the core pattern was completed by adding some resin to the modified finish line of the tooth (Figure 6).

8. The pattern was removed from the tooth, the margins were refined (Figure 7), and it was cast in a cobalt-chromium alloy (Figure 8). The patient was dismissed after sealing the root with a cotton pellet covered by glass ionomer restorative material and removing the retraction cord.

9. During the following appointment, accuracy of the casting into the prepared tooth and the crown were checked separately (Figures 9 and 10), and in combination (Figure 11). A periapical radiograph was taken to confirm the clinical observation before the final cementation.

\section{Discussion}

A case of an endodontically treated tooth with dislodged post and core and a metal-ceramic crown was presented. The importance of the remaining tooth structure in survival rate of endodonticallytreated teeth has been demonstrated by several investigators [5-10].

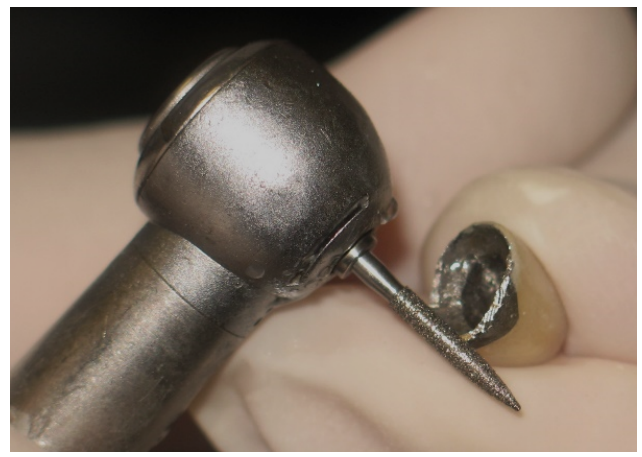

Figure 4. Modification of the crown margin.

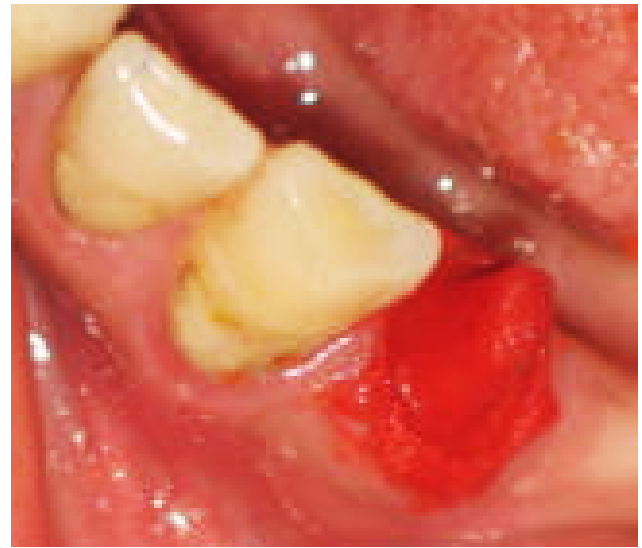

Figure 5. Post and core pattern after crown removal.

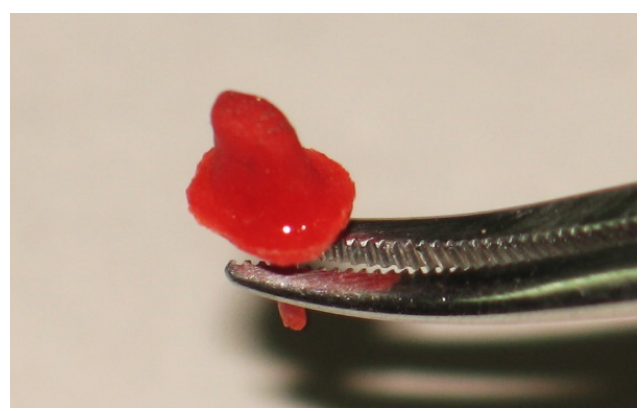

Figure 6. Post and core pattern before casting. 


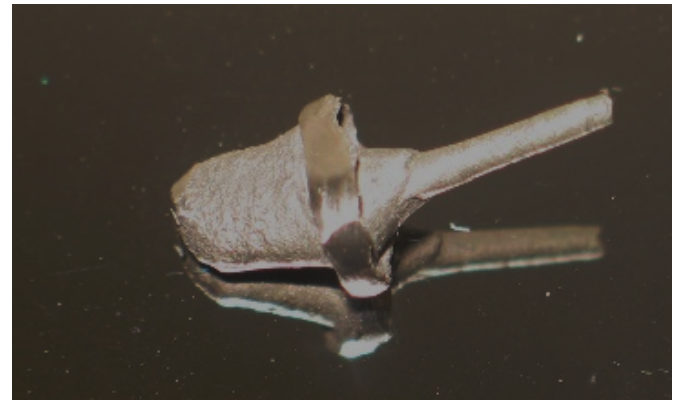

Figure 7. Cast post and core.

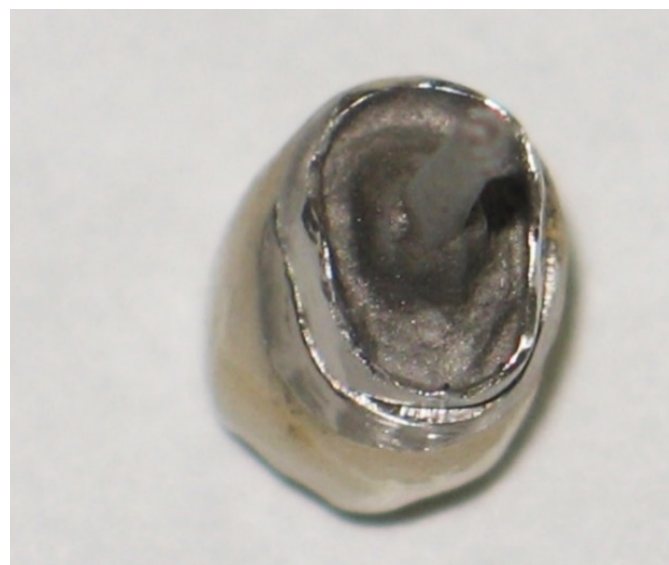

Figure 8. Cast post and core try-in inside the crown.

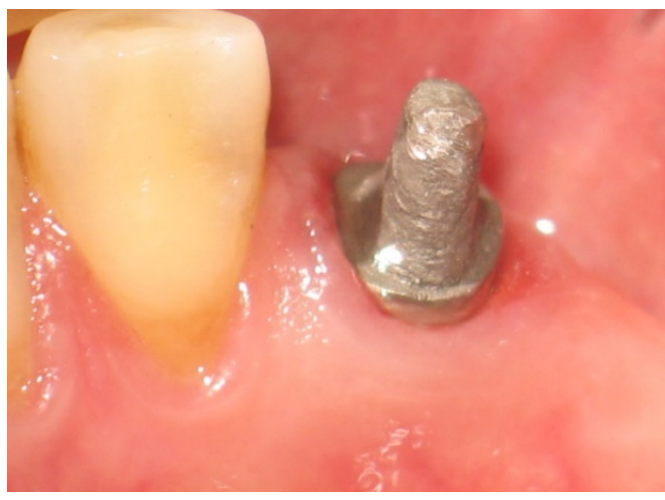

Figure 9. Cast post and core try-in on the tooth.

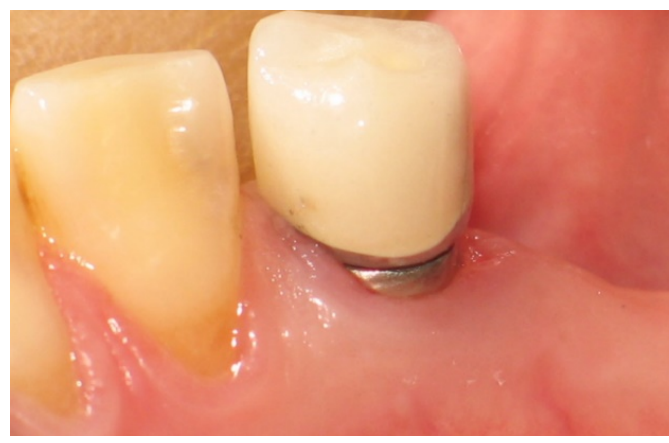

Figure 10. Cast post and core and crown before cementation.

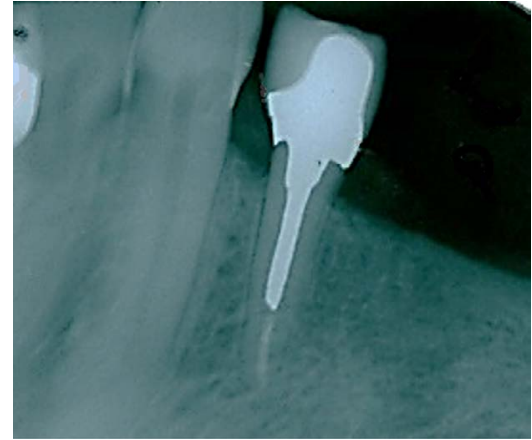

Figure 11. Periapical radiograph of cast post and core and crown before cementation

In the present case, the most obvious etiology for the dislodgement of the crown was inadequate ferrule (less than $1.5 \mathrm{~mm}$ ). Subgingival extension of the finish line was needed to overcome this problem. Although a more acceptable result would have been expected by increasing the crown length surgically, the reduction of bone would have compromised the adjacent tooth in addition to lowering the prognosis of a possible future implant [11].

Another possible cause of the dislodgement of the post-crown complex was the use of a prefabricated post in a single-rooted tooth. A cylindrical prefabricated post does not provide the anti-rotational feature and, in addition, the connection of the core material (in this case, a composite resin) to this structure is unreliable. $[8,11]$ In this case report, a metal cast post and core was used to overcome this complication.

\section{Conclusion}

Retrofitting a cast post and core to an existing crown is a viable alternative to extraction, surgical crown-lengthening procedure, or remaking of the entire prosthesis. Patients need to be informed of the short-term nature of this treatment and understand their options for more predictable treatment modalities.

\section{References}

1. Hardie JM (1982) The microbiology of dental caries. Dent Update 9: 199-200.

2. Holloway PJ, Moore WJ (1983) The role of sugar in the etiology of dental caries. $J$ Dent 11: 189-213. [Crossref]

3. Southam JC, Soames JV (1993) Oral pathology (2nd ed.) Oxford: Oxford Univ Press ISBN 0-19-262214-5.

4. Selwitz RH, Ismail AI, Pitts NB (2007) Dental caries. Lancet 369: 51-59.

5. Mjor IA (2005) Clinical diagnosis of recurrent varies. J Am Dent Assoc 136: 1426-1433.

6. Ng CC, Dumbrigue HB, Al-Bayat MI, Griggs JA, Wakefield CW (2006) Influence of remaining coronal tooth structure location on the fracture resistance of restored endodontically treated anterior teeth. J Prosthet Dent 95: 290-296. [Crossref]

7. Sorensen JA, Engelman MJ (1990) Ferrule design and fracture resistance of endodontically treated teeth. J Prosthet Dent 63: 529-536.

8. Morgano SM, Rodrigues AHC, Sabrosa CE (2004) Restoration of endodontically treated teeth. Dent Clin N Am 48: 397-416.

9. Sorensen JA, Martinoff JT (1984) Intracoronal reinforcement and coronal coverage: a study of endodontically treated teeth. J Prosthet Dent 51: 780-784.

10. Libman WJ, Nicholls JI (1995) Load fatigue of teeth restored with cast posts and cores and complete crowns. Int J Prosthod 8: 529-536.

11. Jotkowitz A, Samet N (2010) Rethinking ferrule--a new approach to an old dilemma 10: 25-33. [Crossref]

Copyright: (C2018 Dashti MH. This is an open-access article distributed under the terms of the Creative Commons Attribution License, which permits unrestricted use, distribution, and reproduction in any medium, provided the original author and source are credited. 